\section{Treatment and Survival after Massive Overdose of Adrenaline}

Brit. med. F., 1967, 4, 38

Infiltration of solutions of adrenaline is often used to produce a degree of haemostasis, and though dilutions vary considerably the normal maximum dose is restricted to about 0.5 to $1 \mathrm{mg}$., while reported maximum tolerated doses with survival are in the order of 7 to $8 \mathrm{mg}$. (Freedman, 1955). This paper reports the inadvertent subcutaneous injection of $16 \mathrm{ml}$. of the undiluted $1: 1,000$ solution ( $16 \mathrm{mg}$.). The patient survived with no residual disability, and consideration of the treatment used may be of benefit to anyone faced with a similar situation.

\section{CASE REPORT}

An otherwise healthy woman aged 23 was admitted to hospital for tympanoplasty under general anaesthesia. Six months previously she had had a left mastoidectomy and a right cortical mastoidectomy and on each occasion anaesthesia with thiopentone, suxamethonium, nitrous oxide, oxygen, and halothane was entirely uneventful. As it was planned to use a local injection of adrenaline, anaesthesia was induced with thiopentone, and endotracheal intubation under suxamethonium was followed by intermittent positive ventilation with nitrous oxide and oxygen, relaxation being maintained by :ubocurarine.

After induction an intravenous infusion of $5 \%$ dextrose was set up while the preliminary surgical procedures were taking place. After infiltration of adrenaline, which was thought to be $1: 200,000$ dilution, the patient's pulse rate became uncountable and her blood pressure rose to unrecordable figures. It was realized that a $1: 1,000$ dilution of adrenaline had been used and the patient had then received $16 \mathrm{mg}$. of adrenaline.

Trimetaphan camsylate (Arfonad) $500 \mathrm{mg}$. was immediately added to the infusion and run in rapidly while $5 \mathrm{mg}$. of phentolamine (Rogitine) was given into another vein. Within two minutes the pulse rate fell slightly, though it was still too fast to count, and the blood pressure fell to $190 \mathrm{~mm}$. $\mathrm{Hg}$ systolic from its previous value of over $300 \mathrm{~mm}$. Hg. Diastolic pressure was difficult to record, but the venous pressure was obviously grossly raised, as shown by the difficulty in maintaining any intravenous infusion during the next three hours. This difficulty persisted in spite of a large catheter inserted into the saphenous vein, and on occasions a pressure pump was required to maintain the infusion.

When about $250 \mathrm{mg}$. of trimetaphan had been given quickly, over 20 minutes, the pulse rate settled to approximately 150 a minute, the blood pressure falling to about $200 \mathrm{~mm}$. $\mathrm{Hg}$ systolic and remaining at this level during the next one and a half hours. When a further $100 \mathrm{mg}$. had been given more slowly (over the next halfhour) the systolic blood pressure fell to $50 \mathrm{~mm}$. $\mathrm{Hg}$ and the ganglion-blocking drug was discontinued. The pressure remained between 70 and $90 \mathrm{~mm} . \mathrm{Hg}$ for the next 36 hours despite the intravenous administration of $200 \mathrm{mg}$. of hydrocortisone. Methylamphetamine (Methedrine) $2.5 \mathrm{mg}$., given during this period of hypotension when the systolic pressure was $80 \mathrm{~mm}$. $\mathrm{Hg}$, produced a transient rise to $140 \mathrm{~mm}$. $\mathrm{Hg}$. Two days after the incident the pressure began to rise spontaneously and reached $120 / 70$ by the fourth postoperative day. The pulse rate also took a long time to settle and was not under 100 until the fourth postoperative day.

It is interesting to note that when the error was first realized the appearance of the patient was normal, but within five minutes this had changed to a state reminiscent of acute peripheral circulatory failure with cold white skin. This latter persisted for several days and was the most striking feature of this case.

The patient was discharged home on the eighth day with no residual disability, and subsequent progress has been entirely satisfactory.

\section{COMMent}

The choice of anaesthetic in this case was fortunate, because had nitrous oxide, oxygen, and halothane been used (as on the previous occasions) it is very likely that the patient would have developed ventricular extrasystoles or even ventricular fibrillation (Millar, Gilbert, and Brindle, 1958 ; Rosen and Roe, 1963). The use of controlled ventilation was also favourable in that it maintained a low $\mathrm{PCO}_{2}$ and prevented a rise in endogenous catecholamine secretion.

After realizing the error in the dose of adrenaline it was decided to continue with the proposed operation, because it was felt that the minor surgical procedure would not materially affect the patient and that continued sedation and intermittent positive-negative ventilation would probably be required for treatment. Marked central stimulation was expected with the massive dose of adrenaline, and if the patient had been allowed to wake the probable restless agitated state with raised venous pressure and inadequate tissue perfusion would have been undesirable. Adequate pulmonary ventilation with an oxygenrich mixture seemed essential and this could easily be provided with the anaesthetic technique in use.

It is not proposed to discuss the possible effects of very large doses of adrenaline, as much of this would be pure speculation. Hypertension, tachycardia, and vasoconstriction were the presenting symptoms in this case, and treatment with a ganglion-blocking drug (trimetaphan) was aimed at rapidly reducing the systolic blood pressure.

It is difficult to explain the prolonged period of hypotension that occurred. In view of the expected duration of trimetaphan it is not likely to be a factor. One might argue that its use was continued longer than necessary, but in view of the persisting skin vasoconstriction this also seems unlikely. Our knowledge of the relative duration of action of the alpha and beta effects of the catecholamine is not such as to throw any light on the subject, but the answer may well lie therein.

Michael A. Lewis, M.B., F.F.A. R.C.S.I., Department of Anaesthetics, the Queen's University of Belfast, Northern lreland.

\section{REFERENCES}

Freedman, B. J. (1955). Lancet, 2, 575.

Millar, R. A., Gilbert, R. G. B., and Brindle, G. F. (1958). Anaesthesia, $13,164$.

Rosen, M., and Roe, R. B. (1963). Brit. F. Anaesth., 35, 51. 